\title{
Self-compassion to decrease performance anxiety in climbers: A randomized control trial
}

- In climbing, anxiety may impair performance

- Self-compassion was hypothesized to decrease performance anxiety

- A two-week randomized control trial was used to investigate the effect of selfcompassion on somatic and cognitive anxiety in sixty climbers

- In the posttest, the self-compassion intervention group showed increased selfcompassion and decreased somatic performance anxiety compared to the waiting list control group

- No changes in cognitive performance anxiety were found

- The results suggest that self-compassion could be considered as a possible intervention to reduce physical symptoms of performance anxiety

Röthlin, P., \& Leiggener, R. (2021). Self-compassion to decrease performance anxiety in climbers: A randomized control trial. Current Issues in Sport Science (CISS), 6: 004. https://doi.org/10.36950/2021ciss004 